\title{
Total thyroidectomy: Conventional suture ligation technique versus sutureless techniques, Sohag experince
}

\author{
Original \\ Article \\ Islam. A. Amer', Abd-El-Aal Ali Saleem², Osama Abdullah Abdul Raheem ${ }^{2}$ \\ ${ }^{l}$ Maxillofacial, Head and Neck Surgery Unit, Department of ${ }^{1,2}$ General Surgery, Faculty of \\ Medicine, Sohag University, Egypt.
}

\begin{abstract}
Background: The thyroid gland is one of the highly vascular tissues in the body. Hemostasis is one of the important and essential components of the procedure. Nowadays with the widespread use of energy instruments like ultrasonic coagulation (Harmonic Scalpel, Ethicon) and bipolar control (LigaSure, Valleylab) or cutting and hemostasis which integrates new approaches to vessel ligation and division without increase the postoperative complications. In a prospective comparative analysis of open complete thyroidectomy, this work aimed to examine the effect of modern suture ligation procedures using the Harmonic ${ }^{\circledR}$ process in comparison with conventional suture ligation.

Patients and Methods: This was a prospective comparative analysis at Maxillofacial, Head, and Neck Surgery Unite in the General Surgery Department, Faculty of Medicine, Sohag University in Sohag, Egypt. The patients were divided into two groups; the first group included patients operated with the Harmonic ${ }^{\circledR}$ Focus or Sutureless Thyroidectomy (S technique), and the second group included patients receiving traditional thyroidectomy ( $\mathrm{C}$ group).

Results: Between September 2016 and September 201992 patients with thyroid disorder were registered for this research. Fifty patients (54.3 percent) had complete sutureless thyroidectomy and 42 patients (45.6 percent) had conventional complete thyroidectomy, mean sutureless thyroidectomy age was (42.53) years, and typical group age was (45.74) years. Duration of operation: blood loss Intraoperative and postoperative, drain, transient hypocalcemia, general postoperative complications, and hospital stay were considerably lower in the Sutureless Thyroidectomy group. No significant difference between the two groups concerning the laryngeal nerve's recurring function.

Conclusion: Sutureless thyroidectomy is the recommended treatment for treating most thyroid disorders, because it has had reduced operation time, reduced clinical complications incidence, and successful operating outcomes. Harmonic Concentration (HF) is a safe, reliable, and time-saving strategy.
\end{abstract}

Key Words: Harmonic thyroidectomy, suturless thyroidectomy, total thyroidectomy.

Received: 31 October 2020, Accepted: 23 December 2020

Corresponding Author: Islam. A. Amer, Department of General Surgery, Faculty of Medicine, Sohag University, Egypt, Tel.: 00201017766441, E-mail: dr.islamamer1981@gmail.com

ISSN: 2090-0740, 2021, Vol.22

\section{INTRODUCTION}

The thyroid gland is one of the human body's most vascularised glands. The removal requires careful hemostasis to avoid intraoperative complications and obtaining good visualization of the surgical field and to preserve the parathyroid glands and recurrent laryngeal nerves. ${ }^{[1]}$

In $925 \mathrm{AD}$ the first total thyroidectomy for goiter was reported by Abu al-Qasim Al zahrawy. Emil Theodore Kocher was the first to use precise surgical technique and meticulous hemostasis to reduce the mortality rate to $0.5 \%$ in more than 5000 thyroidectomies. ${ }^{[2]}$ Due to His work in thyroid surgery, he got a Nobel Prize in $1909^{[3]}$.

Total thyroidectomy (TT) is the most common treatment for endocrine gland surgery. It is the most comfortable choice for treating many thyroid disorders through surgery ${ }^{[4]}$.
With classic methods such as tie and lock, electrocautery, clips, or fibrin adhesive, we have accomplished hemostasis which is time-consuming and packed with knot slipping danger, upsetting and thermal trauma. ${ }^{[5]}$

Vascular Sealing Device (VSD) close the vascular structures by coagulating them. The coagulated vessels could transact safely without requiring any additional ligation. Although VSDs are not suitable for large and main vessels. Intraoperatively in thyroid surgery, all vessels reached will coagulate which leads to a decrease time of the operation when we use tie and sutures and reduce blood loss for thyroid gland surgery. ${ }^{[6]}$

VSD is an effective aid in endoscopic thyroid surgery. Since the invention of laparoscopic surgery, specialized hemostasis techniques for thyroid surgery, including the harmonic scalpel, and the LigaSure vessel sealing mechanism (LVSS). ${ }^{[6]}$ 
Harmonic Scalpel (HS) is high frequency $(55 \mathrm{kHz})$ ultrasonically activated coagulation shearing ultrasound waves that can sever vessels up to $5 \mathrm{~mm}$ to $7 \mathrm{~mm}$ in diameter. The active HS blade vibrates longitudinally against an inactive blade resulting in cutting and coagulation. For monopolar or bipolar electrocautery $50^{\circ} \mathrm{C}$ to $100^{\circ} \mathrm{C}$ compared to $150^{\circ} \mathrm{C}$ to $400^{\circ} \mathrm{C}$. Therefore tissues in the surrounding area should experience less thermal damage than electrocautery ${ }^{[7]}$.

Harmonic Scalpel's device is a great accomplishment as a tool with many views and is now used widely in laparoscopic operations to simplify, save time, and fewer complications. ${ }^{[8]}$

Nowadays with the massive emergence of energy instruments such as ultrasonic coagulation (Harmonic Scalpel, Ethicon) and bipolar energy (LigaSure, Valleylab) for cutting and hemostasis incorporating new vessel ligation and separation techniques without increasing the risk of postoperative complications. ${ }^{[9]}$

In a prospective comparative study of open full thyroidectomy, this review aimed to compare the effects of applying the Harmonic ${ }^{\circledR}$ Scalpel and traditional suture ligation techniques in total thyroidectomy.

\section{PATIENTS AND METHODS:}

\section{The study design}

Prospective comparative randomized analysis study evaluating TT results using traditional suture ligation technique versus sutureless technique. This was a Prospective comparative study at the Maxillofacial, Head and Neck Surgery Unit in the General Surgery Department at Sohag University Hospital, Egypt. All participants were given written informed consent to participate, after receiving an explanation of the study protocol, including both types of operation and possible complications. Patients were split into two categories at random; the first group included patients with sutureless thyroidectomy (S group), while the second group included patients with conventional thyroidectomy (C group).

\section{Study population}

The study included patients complaining of thyroidal disease who need surgical treatment. The study started from September 2016 to the end of September 2019. Between September 2016 and September 2019, the Maxillofacial, head and Surgery Unit in the Department of Surgery, University of Sohag, Sohag, Egypt, operated on 92 patients with thyroid disease needing surgical intervention and meeting our inclusion criteria patients were divided into two classes: Sutureless group total thyroidectomy and traditional group total thyroidectomies 50 patients (54.3 percent) had a sutureless overall thyroidectomy and 42 patients (45.6 percent) had a traditional overall thyroidectomy.

\section{Inclusion criteria}

All patients with thyroidal disease candidate for TT presented to Maxillofacial, Head and Neck Surgery Unit, General Surgery Department in Sohag University Hospital were eligible for the study. All the data were recorded, tabulated, and statistically analyzed regarding preoperative, operative, and postoperative data.

\section{The exclusion criteria:}

1) A need for neck dissection in the central or lateral compartment.

2) Previous irradiation of the neck.

3) Recurrent goiter.

4) Radio-iodine ablation.

5) Hemithyroidectomy, subtotal thyroidectomy

\section{Setting:}

This study was conducted at the University Hospital in Sohag. Each patient will be numbered randomly by a sealed (closed) envelope method either 1, 2 to determine which technique was to be applied to them. Conventional Suture Ligation Technique (Group C), patient number 2 was treated using Harmonic Focus using a sutureless technique (Group S). Every patient has the same opportunity to become part of both classes. All patients had signed TT and gave informed consent to join the study.

This research was approved by the Ethics Committee at Sohag University Hospital, and each patient received informed consent. Both patients were tested using surgical, clinical, and vocal cord analysis.

Preoperative data were prospectively reported about age, gender, Thyroid diagnosis, thyroid function test, and calcium serum preoperative. The patients were clinically and biochemically examined, in addition to the vocal cord function tests.

Surgical techniques: The surgical time from skin incision to skin closure was estimated to be in minutes. Both surgical operations were performed with endotracheal intubation under general anesthesia. Cervical linea alba was opened after the division of the muscle platysma. Very large goiters required strap muscle division. The lateral thyroid lobe, its vascular pedicles, was gradually dissected away from the strap muscles ligated with Vicryl ${ }^{\circledR} 2 / 0$ suture [in conventional thyroidectomy group] or coagulated and divided with Harmonic ${ }^{\circledR}$ FOCUS (Harmonic - Ethicon Endo-Surgery INC - Johnson and Johnson Medical SPA, Somerville, NJ) in Sutureless thyroidectomy group. 


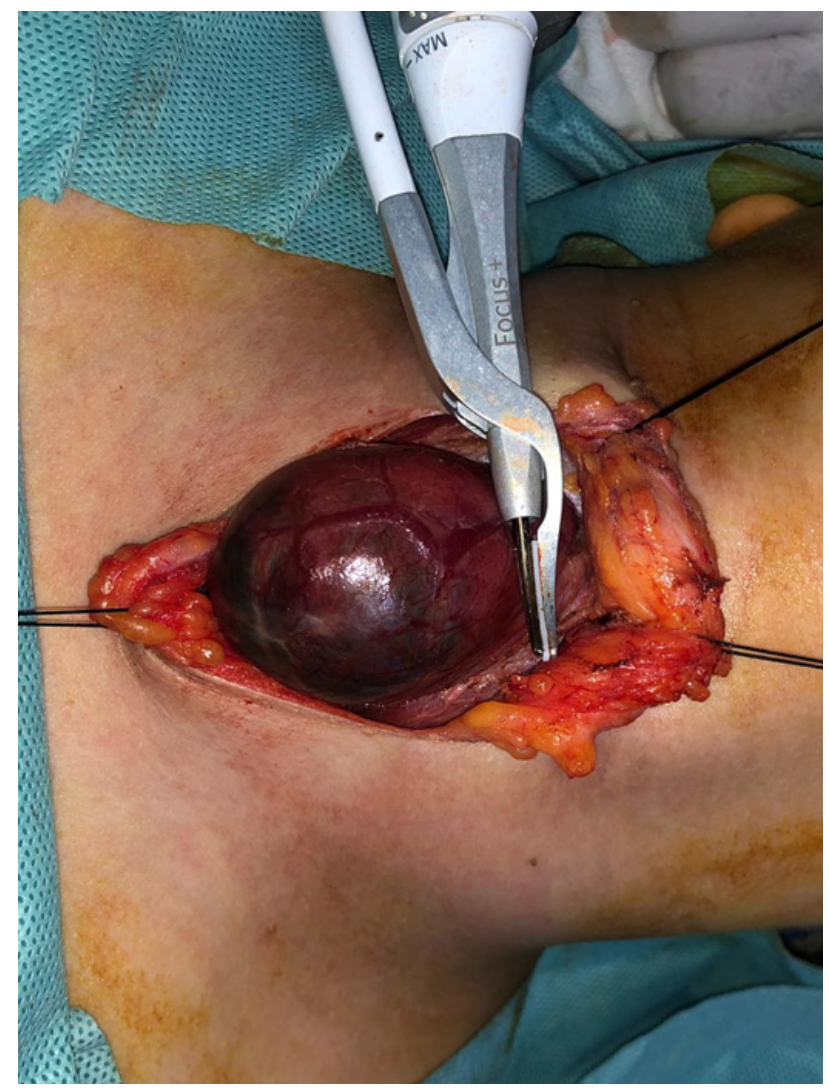

Fig. 1: Thyroidectomy with harmonic focus (Sutureless)

Since the recurrent laryngeal nerves and parathyroid glands were explored, the thyroid lobe was gradually dissected off the trachea and ligate the inferior thyroid arteries and dissected off the thyroid capsule. As part of the monitoring regimen for determining blood loss rates over the first 48 hours, a suction drain was placed daily into the thyroid bed after hemostasis was reached. Vicryl ${ }^{\circledR} 3 / 0$ used to close the Lina Alba and Cervical incision.

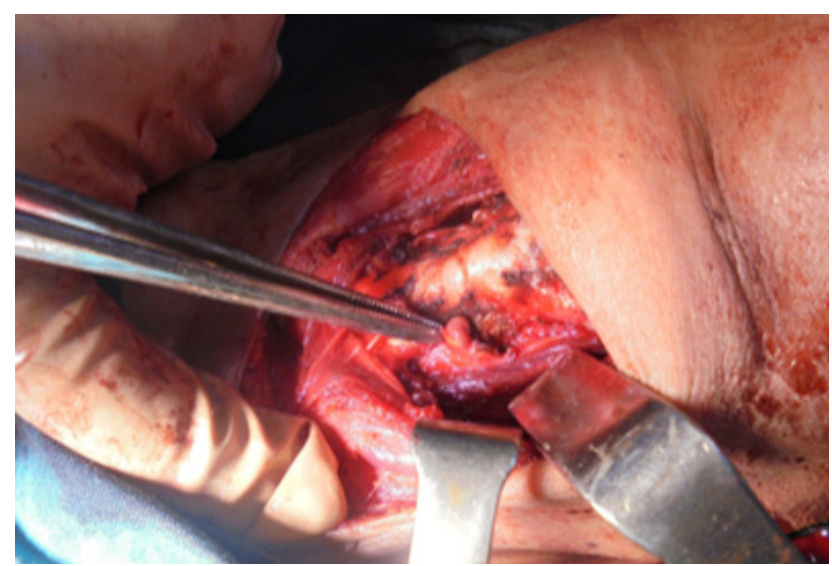

Fig. 2: Sutureless thyroidectomy with harmonic focus with preservation of the parathyroid gland

\section{Operative time}

The time elapsed between skin incision and the end of wound closure.

\section{Intra-operative blood loss}

It was measured from the increase in weight of the bloodied swabs or measured from intraoperative drainage.

\section{The postoperative evaluation:}

Examination of both preoperative and postoperative parameters (duration of the operation, drainage rate, postoperative serum calcium levels), surgical complications (paralysis of the laryngeal nerves, hypoparathyroidism, vomiting, and wound infection), hospital stay length, reoperation, and histopathological evaluation. The serum calcium levels are postoperatively monitored on the $1 \mathrm{st}$, 2nd, 10th, and 30th days. Postoperative pain was evaluated by the number of NSAIDS ampoules used during the first 24 postoperative hours.

\section{Frequency follow-up after discharge}

During the first month, once every two weeks.

From the second to the fifth month, once every month.

From the sixth to twelfth month, one follow-up visit.

\section{What to monitor?}

1) Thyroid function tests (T3, T4, TSH)

2) Respiration

3) Voice

4) Wound

5) Hypothyroid manifestations

6) Histopathological diagnosis of removed thyroid

7) Serum calcium level

Hypocalcaemia: was diagnosed as a serum calcium level below $8.0 \mathrm{mg} / \mathrm{dL}(2.00 \mathrm{mmol} / \mathrm{L})$ (reference range, $8.0-10.5 \mathrm{mg} / \mathrm{dl}(2.00-2.60 \mathrm{mmol} / \mathrm{L})$ (Ferri et al, 2011).

\section{Hypoparathyroidism}

-Persistenthypoparathyroidism:Hypoparathyroidism verified by PTH determination that has not recovered by the sixth postoperative month.

-Transient hypoparathyroidism: Hypoparathyroidism with verification of recovery of PTH levels within 6 months postoperative.

Recurrent Laryngeal Nerve (RLN) palsy, was considered because there is a proof of healing was evident within 6 months of postoperative follow-up. 


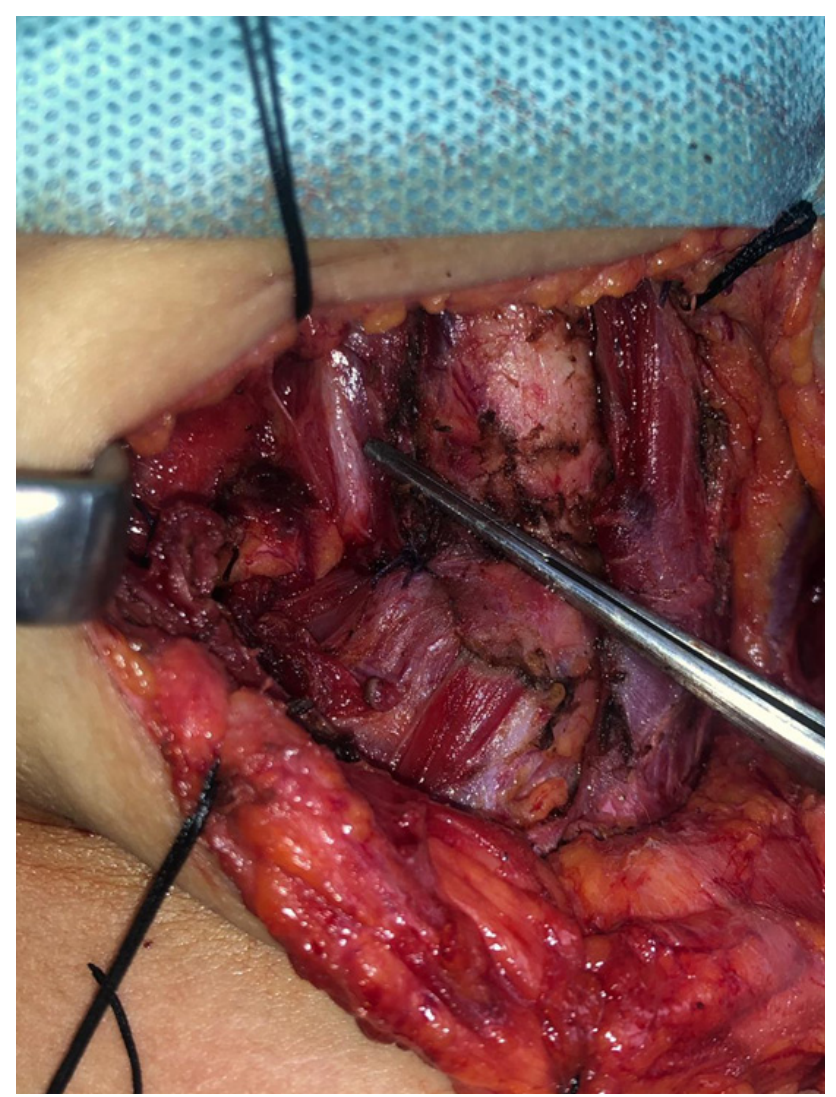

Fig. 3a: Final view (Total thyroidectomy by a sutureless technique by harmonic focus) with appearance of Recurrent laryngeal nerve.

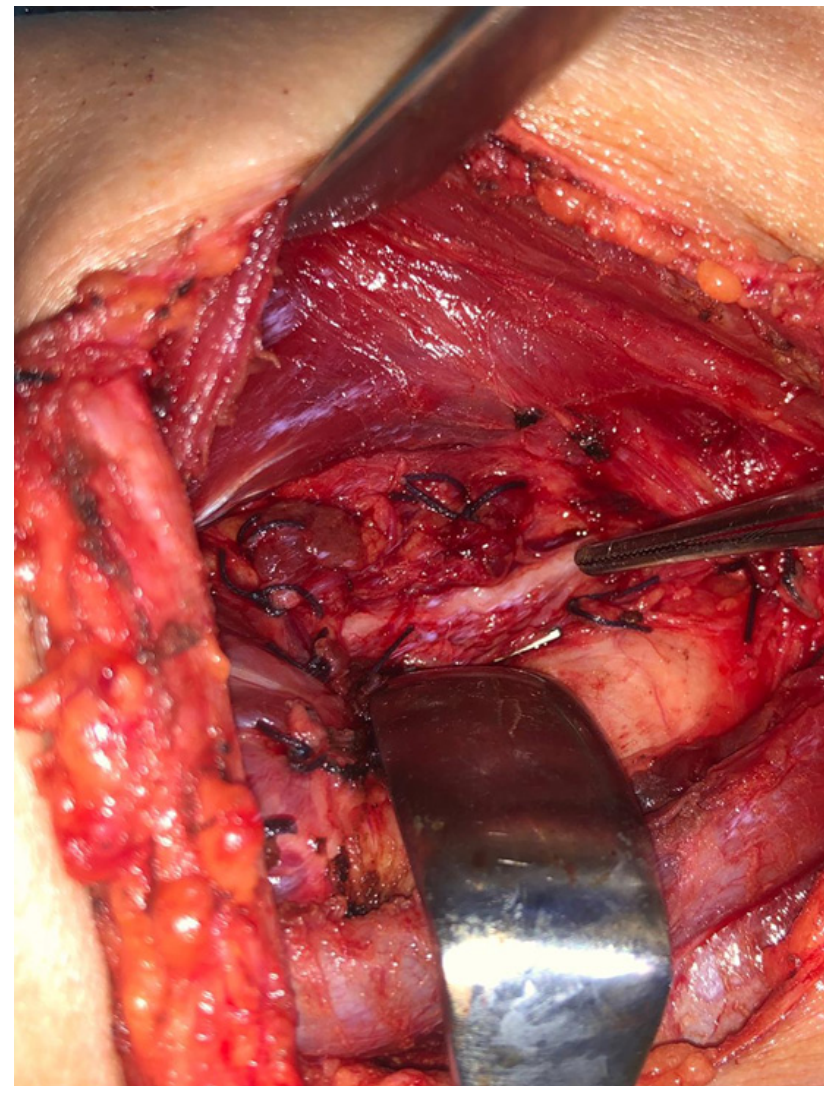

Fig. 3b: Final view (Total thyroidectomy by a sutureless technique by harmonic focus) with appearance of Recurrent laryngeal nerve.

\section{Method of the statistical study}

The tests were interpreted and analyzed using the Social Sciences Statistical Kit (SPSS Inc., version 20, Chicago, USA); statistical analysis of the differences between groups was conducted using the 2-sample t-test and the 2-sample $\mathrm{t}$-test. Results were presented as mean \pm standard deviation ( SD) for numerical variables, and number (percentage) for non-parametric variables. Has been a P-value of $<0.05$.

\section{The 2-sample t-test:}

A hypothesis test that is used to determine questions related to the mean in situations where data is collected from two random data samples. The two-sample T-test is often used for evaluating the means of two variables or distinct groups, providing information as to whether the means between the two populations differ ${ }^{[10]}$ Applied to two independent groups when the In addition to assuming that the data is from a normal distribution, the sample size of the two groups may or may not be equal, it is often assumed that the standard deviation (SD) is roughly the same for both groups. Compares the means by t-test for the two Information Classes. The test decides whether the data originates from the same population or not, the mean difference is measured (this can be a positive or negative value); a confidence interval of 95 percent is also determined for the mean difference. It calculates a $p$-value where $p$ is the probability of a false-positive event. ${ }^{[11]}$

\section{The chi-squared test( $\chi 2$ test)}

The chi-squared test is used to determine whether there is a significant difference between the expected frequencies and the observed frequencies in one or more categories. The chi-square independence test is a procedure for testing if two categorical variables are related in some populations. $^{[12]}$

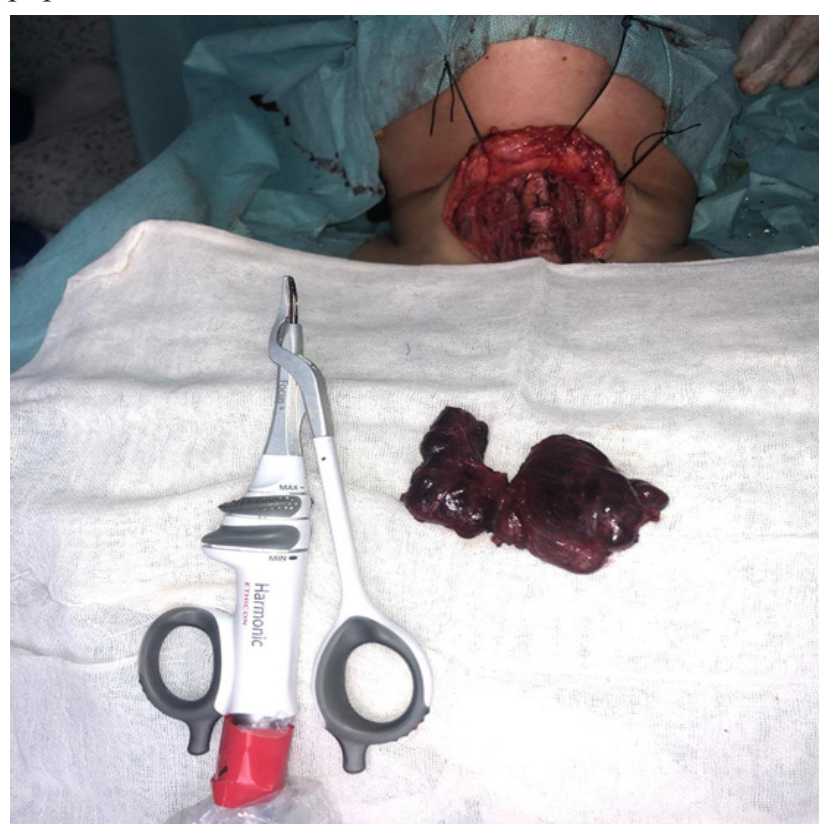

Fig. 4a: Final view (Total thyroidectomy by a sutureless technique by harmonic focus). 


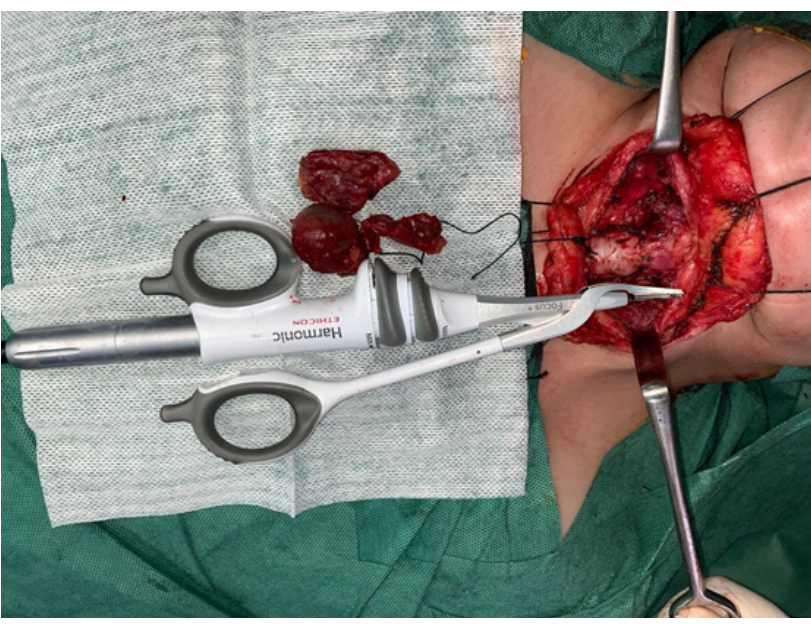

Fig. 4b: Final view (Total thyroidectomy by a sutureless technique by harmonic focus).

\section{RESULTS:}

Between September 2016 and September 2019, the Maxillofacial, head and Surgery Unit in the Department of Surgery, University of Sohag, Sohag, Egypt, operated on 92 patients with thyroid disease needing surgical care and meeting our inclusion criteria patients were divided into two classes: Sutureless group total thyroidectomy and traditional group total thyroidectomies 50 patients (54.3 percent) had a sutureless overall thyroidectomy and 42 patients (45.6 percent) had a traditional overall thyroidectomy, with a mean age of $(42.53 \pm 12.139)$ years for sutureless thyroidectomy and $(45.74 \pm 13.952)$ years for a traditional community, $p=0.166$ not important. Within the thyroidectomy group, Sutureless 46 were female and 4 were male while 37 were female and 5 were male in the traditional community, $p$-value $=0.582$ was not important. Indications of surgery are given in (Table 1).

Table 1: Demographic data

\begin{tabular}{|c|c|c|c|c|c|}
\hline & \multicolumn{2}{|c|}{ Group $S(n=50)$} & \multicolumn{2}{|c|}{ Group C $(n=42)$} & \multirow{2}{*}{ P.value } \\
\hline & No & $\%$ & No & $\%$ & \\
\hline \multicolumn{6}{|l|}{ Age group } \\
\hline Mean \pm SD & \multicolumn{2}{|c|}{$42.53 \pm 12.139$} & \multicolumn{2}{|c|}{$45.74 \pm 13.95$} & 0.241 \\
\hline \multicolumn{6}{|l|}{ Gender } \\
\hline Male & 4 & 8 & 5 & 11.9 & \multirow[b]{2}{*}{$0.029^{*}$} \\
\hline Female & 46 & 92 & 37 & 88.1 & \\
\hline
\end{tabular}

Independent samples T-Test and Chi-square test,

$*$ Statistically significant difference $(p<0.05)$;

**Highly statistically significant difference $(p<0.01)$.

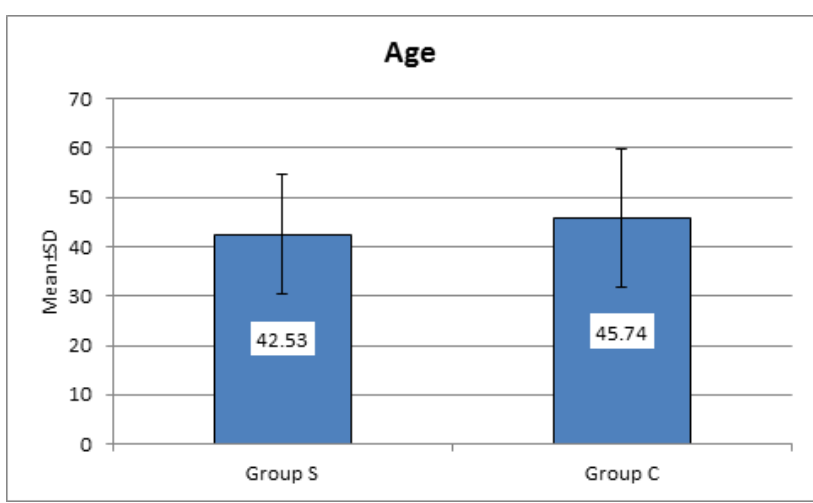

Fig. 5: Clustered column chart showing (Mean $\pm \mathrm{SD}$ ) of age distribution between two groups.

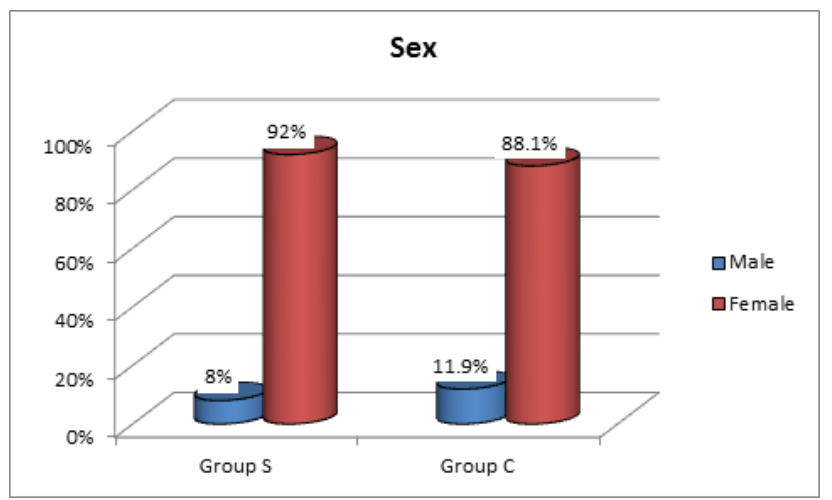

Fig. 6: Clustered cylinder chart showing the percentage of sex distribution between two groups.

Table 2: Indications for surgery in both groups

\begin{tabular}{lcccccc}
\hline $\begin{array}{l}\text { Indications } \\
\text { for surgery }\end{array}$ & Total & \multicolumn{2}{c}{$\begin{array}{c}\text { Group S } \\
(\mathrm{n}=50)\end{array}$} & \multicolumn{2}{c}{$\begin{array}{c}\text { Group C } \\
(\mathrm{n}=42)\end{array}$} & $\begin{array}{c}P . \\
\text { value }\end{array}$ \\
& & No. & $\%$ & No. & $\%$ & \\
\hline $\begin{array}{l}\text { Multinodular } \\
\text { goiter }\end{array}$ & 82 & 45 & 90.0 & 37 & 88.1 & \\
$\begin{array}{l}\text { Secondary } \\
\text { toxic goiter }\end{array}$ & 5 & 3 & 6.0 & 2 & 4.8 & 0.783 \\
$\begin{array}{l}\text { Primary } \\
\text { toxic goiter }\end{array}$ & 5 & 2 & 4.0 & 3 & 7.1 & \\
Total & 92 & 50 & 100.0 & 42 & 100.0 & \\
\hline
\end{tabular}

Chi-square test,

* Statistically significant difference $(p<0.05)$;

**Highly statistically significant difference $(p<0.01)$.

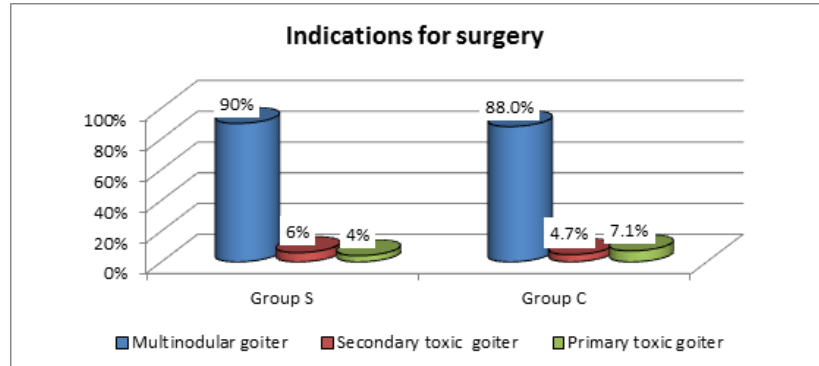

Fig. 7: Clustered cylinder chart showing the percentage of indications for surgery distribution between two groups. 
Table 3: Summarized the operative and post-operative results

\begin{tabular}{|c|c|c|c|c|c|}
\hline \multirow{2}{*}{ Parameter } & \multicolumn{2}{|c|}{ Group $S(n=50)$} & \multicolumn{2}{|c|}{ Group C $(n=42)$} & \multirow{2}{*}{ P-value } \\
\hline & No. & $\%$ & No. & $\%$ & \\
\hline \multicolumn{6}{|l|}{ Operative time (min) } \\
\hline - $\quad$ Mean \pm SD & \multicolumn{2}{|c|}{$55.40 \pm 7.89$} & \multicolumn{2}{|c|}{$108.14 \pm 11.18$} & $<0.001^{* *}$ \\
\hline \multicolumn{6}{|c|}{ Intraoperative blood loss (ml) } \\
\hline - $\quad$ Mean $\pm \mathrm{SD}$ & \multicolumn{2}{|c|}{$33.07 \pm 5.75$} & \multicolumn{2}{|c|}{$75.09 \pm 15.41$} & $<0.001^{* *}$ \\
\hline \multicolumn{6}{|c|}{ Post-operative drainage volume (ml) } \\
\hline - $\quad$ Mean $\pm \mathrm{SD}$ & \multicolumn{2}{|c|}{$19.30 \pm 4.44$} & \multicolumn{2}{|c|}{$47.49 \pm 12.12$} & $<0.001^{* *}$ \\
\hline \multicolumn{6}{|c|}{ Post-operative pain (first 24 hours) } \\
\hline $\begin{array}{l}\text { Need for one } \\
\text { ampoule of NSAIDS }\end{array}$ & 50 & 100.0 & 42 & 100.0 & - \\
\hline $\begin{array}{l}\text { Need for two } \\
\text { ampoules of } \\
\text { NSAIDS }\end{array}$ & 15 & 30.0 & 30 & 71.4 & $<0.001^{* *}$ \\
\hline $\begin{array}{l}\text { Need for more } \\
\text { than two ampoules } \\
\text { of NSAIDs }\end{array}$ & 2 & 4.0 & 10 & 23.8 & 0.468 \\
\hline $\begin{array}{l}\text { Post-operative } \\
\text { complications }\end{array}$ & 2 & 4.0 & 18 & 36.0 & $<0.001^{* *}$ \\
\hline -Hypocalcaemia & 1 & 2.0 & 8 & 16.0 & $0.042^{*}$ \\
\hline - $\quad$ Temporary & 1 & 2.0 & 6 & 12.0 & 0.132 \\
\hline - Permanent & 0 & 0.0 & 2 & 4.0 & 0.518 \\
\hline$-\mathrm{RLN}$ & 0 & 0.0 & 3 & 6.0 & 0.739 \\
\hline - Unilateral & 0 & 0.0 & 2 & 4.0 & 0.518 \\
\hline - $\quad$ Bilateral & 0 & 0.0 & 1 & 2.0 & 0.924 \\
\hline -Wound infection & 0 & 0.0 & 3 & 6.0 & 0.739 \\
\hline $\begin{array}{l}\text { - Postoperative } \\
\text { hematoma }\end{array}$ & 0 & 0.0 & 1 & 2.0 & 0.924 \\
\hline $\begin{array}{l}\text {-Post-operative } \\
\text { seroma }\end{array}$ & 1 & 2.0 & 3 & 6.0 & 0.739 \\
\hline \multicolumn{6}{|l|}{ Hospital stay(days) } \\
\hline - $\quad$ Mean $\pm \mathrm{SD}$ & \multicolumn{2}{|c|}{$1.97 \pm 0.18$} & \multicolumn{2}{|c|}{$4.31 \pm 1.79$} & $<0.001^{* *}$ \\
\hline \multicolumn{6}{|l|}{ Mortality } \\
\hline - $\quad$ Yes & 0 & 0 & 0 & 0 & 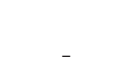 \\
\hline - $\quad$ No & 50 & 100.0 & 42 & 100.0 & - \\
\hline
\end{tabular}

Independent samples T-Test and Chi-square test,

* Statistically significant difference $(p<0.05)$; ** Highly statistically significant difference $(p<0.01)$.

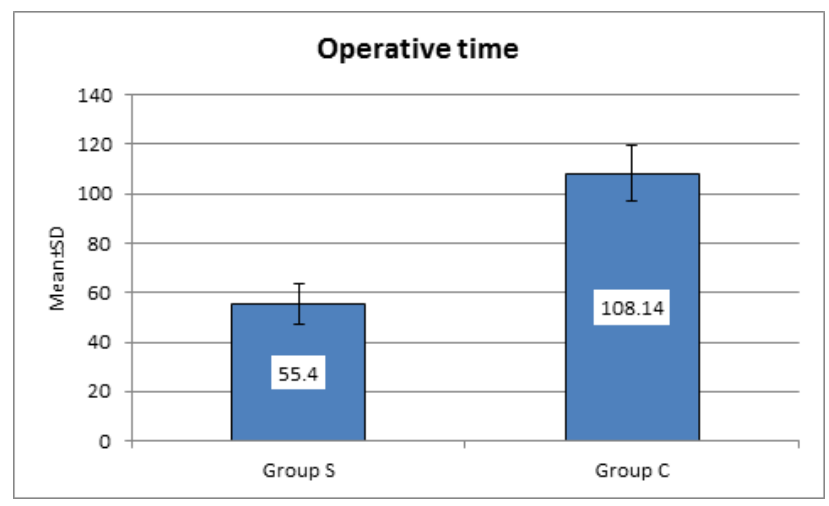

Fig. 8: Clustered column chart showing (Mean \pm SD) of operative time distribution between two groups.

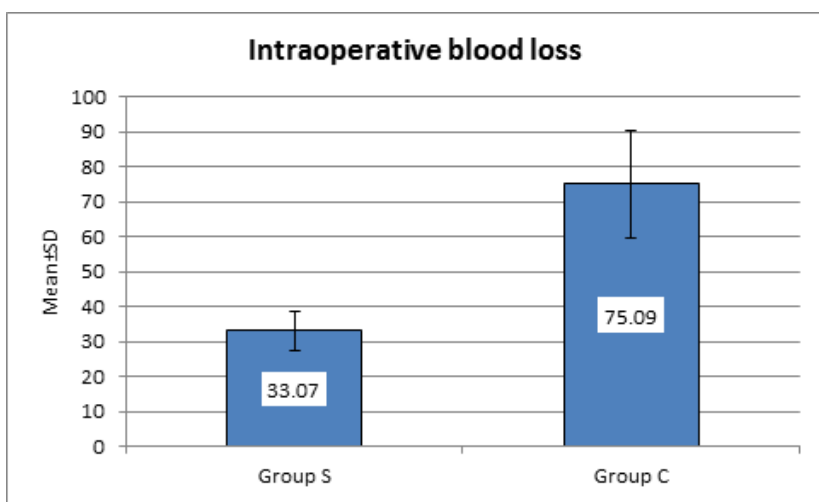

Fig. 9: Clustered column chart showing (Mean \pm SD) of intraoperative blood loss distribution between two groups. 


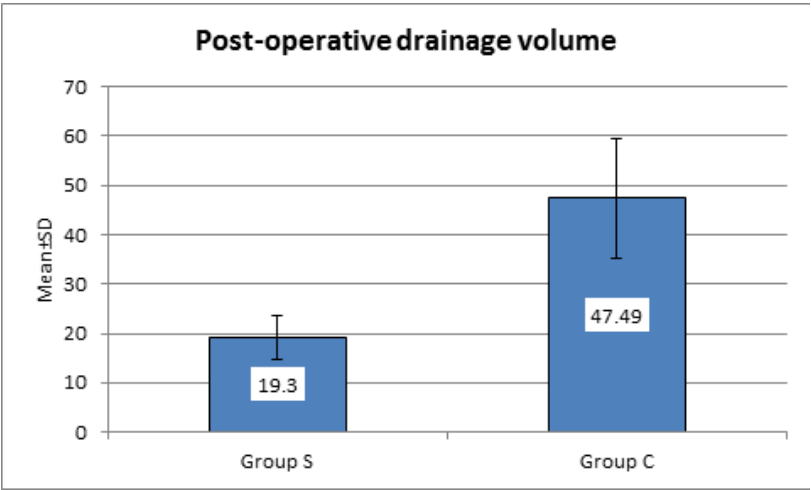

Fig. 10: Clustered column chart showing (Mean \pm SD) of postoperative drainage volume distribution between two groups.

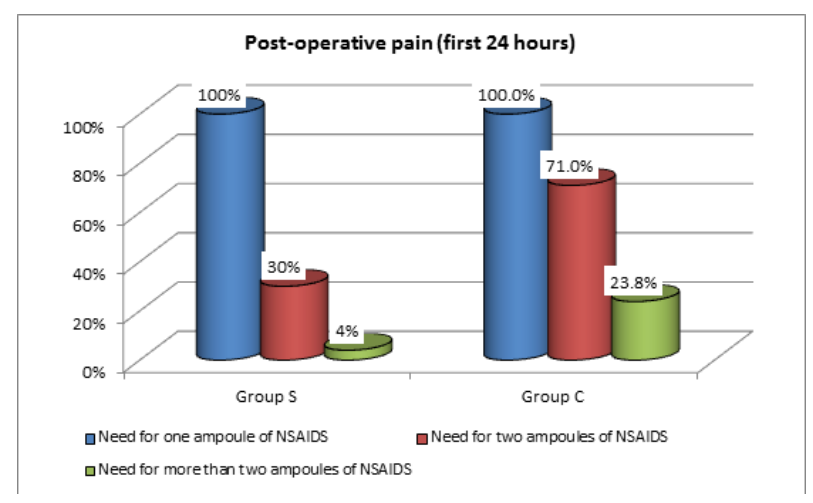

Fig. 11: Clustered cylinder chart showing the percentage of postoperative pain distribution between two groups.

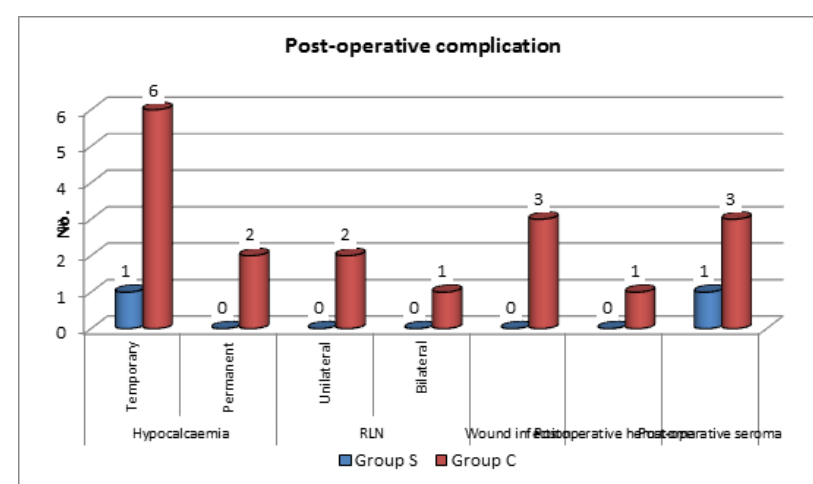

Fig. 12: Clustered cylinder chart showing the percentage of postoperative complication distribution between two groups.

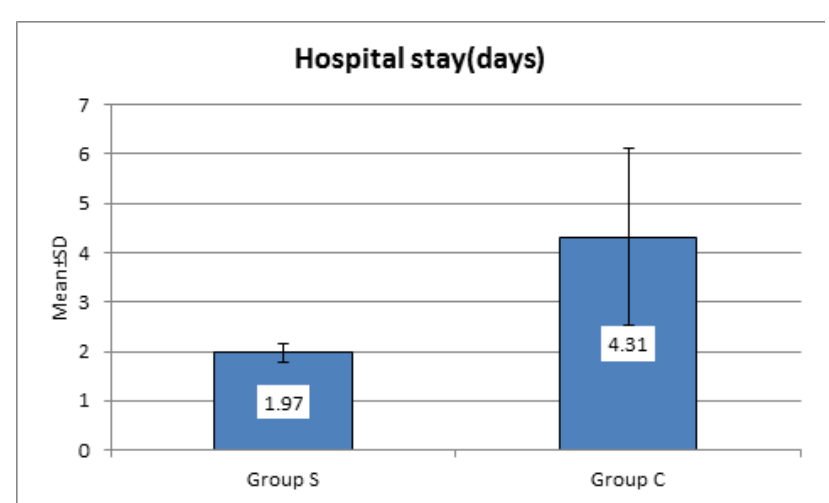

Fig. 13: Clustered column chart showing $(M e a n \pm S D)$ of hospital stay drainage volume distribution between two groups.

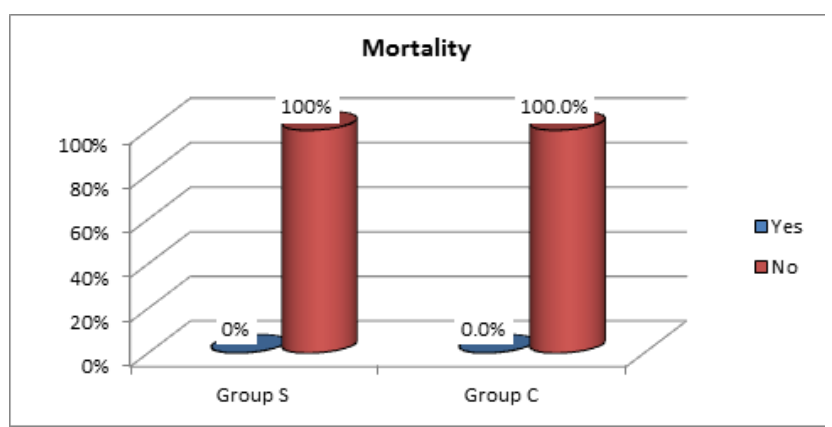

Fig. 14: Clustered cylinder chart showing the percentage of mortality distribution between two groups.

\section{DISCUSSION}

Total thyroidectomy is considered one of the surgical operations most commonly performed. The thyroid gland is considered a highly vascularized organ, and swift and effective hemostasis is a critical stage of treatment. ${ }^{[13]}$

With the introduction and significant advances of energy equipment such as ultrasonic coagulation systems (e.g., Harmonic Scalpel (Ethicon, Washington) SonoSurg (Olympus Medical, Tokyo, Japan) this results in the increased surgical outcome and decreased complications risk. ${ }^{[14]}$

The findings of this study show that harmonic sutureless thyroidectomy substantially reduced operating time, blood loss intraoperative, postoperative drainage rate, transient hypocalcemia, postoperative complications, and hospital stay.

In their meta-analysis, Luca Revelli et al stated that total sutureless thyroidectomy was a healthy, effective, and fast alternative to traditional total thyroidectomy. ${ }^{[15]}$

The benefit of the harmonic orientation is that without the need for clips and suture ligations, it makes the operation simple and ensures strong hemostasis. It dramatically decreased operation time relative to traditional complete thyroidectomy, which was similar to other tests, owing to the reduction of bleeding and effective rapid hemostasis, blood loss, and hypocalcemia in the sutureless community. ${ }^{[14,16]}$

In addition to increasing healing time, sutureless thyroidectomy also reduces the iatrogenic complications involving the thyroid gland, such as neurovascular injuries.

Harmonic focus requires high-frequency mechanical energy for simultaneous tissue coagulation and the gain of cutting. These seals vessels with diameters up to $5 \mathrm{~mm}$ Ensuring precise and reliable 
surgical dissection as in thyroid surgery, with considerable savings in operating time. The thermal lateral damage is limited to $2 \mathrm{~mm}$ above the tissue grasped within the forceps of the system. ${ }^{[18]}$

This analysis showed sutureless and traditional suture ligation operating times; mean \pm SD was $55.40 \pm 7.894$ minutes and $108.14 \pm 1.186$ minutes respectively with a mean $\pm \mathrm{SD}$ of the total $81.77 \pm 9.54$ $P$-value is 0.0001 . There was a significant statistical difference $(p$-value $<0.05)$.

Test by Al-Dhahiry et al.; operating period of suture-free and standard suture ligation groups; mean \pm SD was $92.5 \pm 1.8$ and $113 \pm 10.9$ respectively. They were longer than our two-group, with a statistically meaningful difference, $P$-value $<0.001 .^{[6]}$

The running time of our two classes was less than that of the Peker et al. Study; sutureless and traditional suture ligation classes were $60.359 \pm 12.44$ and $92.92 \pm$ 12.12 respectively with $P$-value $=0.00 .^{[19]}$ The Peker et al. analysis agreed with the conclusions of this paper and suggested comparable running times For standard and suture-free ligation groups, but shorter than our modern group. Chang, and so on. Analyzed 1945 patients with full thyroidectomy (1163 using the Harmonic scalpel sutureless technique) and no clinical variations in postoperative complications were observed, although the mean operation period was slightly lower in the sutureless classes. ${ }^{[20]}$

The study with Suhaimi MB et al. revealed an average running time of 121.29 minutes $^{[21]}$, but in this study, the operating time was shorter; mean \pm $81.77 \pm 9.54 \mathrm{~min}$.

Allan E Seperstien et al. 's study had longer operation time than this report; the sutureless group and typical suture ligation groups; mean and SD were $132 \pm 39$ and $161 \pm 42$ minutes, with statistically relevant difference $P$-value $=0.01$ respectively. ${ }^{[22]}$

For the firfst postoperative cycle, this analysis revealed a postoperative blood drainage volume of 48 hours; sutureless group and typical suture ligation group; mean $\pm \mathrm{SD}, 19.30 \pm 4.442 \mathrm{ml}$ and $47.49 \pm 12.125$ $\mathrm{ml}$ respectively, with a mean $\pm \mathrm{SD}$ of $33.395 \pm$ $8.2835 \mathrm{ml}$. The conventional suture ligation category had the greatest amount of drainage, Whereas the sutureless group had the lowest drainage volume with a statistically meaningful difference $P$-value $=0.0001$.

A study by Al-Dhahiry et al.: reported blood drainage volume for the first postoperative $48 \mathrm{~h}$; sutureless and conventional suture ligation groups; mean $\pm \mathrm{SD}, 89 \pm 16,21 \mathrm{ml}$ and $150 \pm 12,7 \mathrm{ml}$; mean $\pm \mathrm{SD}$ sum was $118 \pm 6,2 \mathrm{ml}$, respectively. The highest drainage volume was for the modern suture ligation group and the smallest volume of drainage group with a statistically important deviation P-value $0.046 \cdot{ }^{[6]}$

The Emanuele $\mathrm{F}$ et al. analysis had in the sutureless group a cumulative amount of drainage fluid smaller than in the CT community; mean \pm SD $37.4 \pm 2.4$ versus $56.1 \pm 4.2$ respectively.

This research indicates operation periods of suturefree and standard suture ligation classes concerning hospital stay; mean \pm SD $1.97 \pm 0.183$ days a day, which is $4.31 \pm 1.795$ days. Substantial statistical variance, the $p$-value was 0.0001 .

Nadim Khan et al . reported median hospital stay in a sutureless group of \pm SD 1/4 $2.2 \pm 0.9$ days; 3.7 \pm 1.3 days in a standard suture ligation group with substantial statistical variance $(p$-value $<0.05) .{ }^{[23]}$

With regards to RLN paralysis, this study had 3 of $65(4.6 \%)$ RLN paralysis patients; 2 patients $(3 \%)$ had unilateral RLN paralysis, and 1 patient $(1.54 \%)$ had bilateral RLN paralysis. The three patients had been treated using traditional suture ligation technique. In Group S (sutureless group) no chronic postoperative laryngeal paralysis exists. The $P$-value is equivalent to 0.38 .

Al-Dhahiry et al.study; had 4 out of $80(5 \%)$ patients with RLN paralysis; 3 patients ( 3.75 percent) had chronic unilateral RLN paralysis and 1 patient $(1.25 \%)$ had bilateral permanent RLN palsy. All these cases belong to the CSL group. the sutureless group had no patient. ${ }^{[6]}$

Regarding postoperative hypocalcemia, (transient or permanent): there were 7 patients had developed post-operative transient hypocalcemia, one patient (2\%) from group $\mathrm{S}$ (sutureless group), and 6 cases from the conventional suture ligation group (14.2\%), P-value was significant (0.024). only 2 cases from conventional suture ligation had developed permanent postoperative hypocalcemia $(4.7 \%)$. No sutureless community patient experienced permanent postoperative hypocalcemia ( 0 percent), $\mathrm{P}$-value is not significant (0.485).

Al-Dhahiry et al. The study included 17 of 80 patients $(21.2 \%)$ with transient hypocalcemia; suturefree group and conventional suture ligation; 4.8, statistically significant, $P$-value $=0.01$. Only one patient experienced persistent hypocalcemia from the traditional suture ligation party, $P$-value $=0.349 .{ }^{[6]}$ 
Giovani et al. report; 38 (19\%) of 200 patients suffered from transient hypocalcemia; sutureless groups and conventional suture ligation; 18 and 20 respectively. ${ }^{[24]}$

The Matteo research included 27 out of 265 patients (10.2 percent) with transient hypocalcemia; traditional suture ligation, suture-free groups; 14, 13 without statistical significance, $P$-value (NS), respectively. ${ }^{[25]}$

One patient (1.08 percent of all patients) experienced bleeding during the first postoperative $48 \mathrm{~h}$ during this analysis. This patient ( 2.83 percent) was from the traditional suture ligation group and the patient was reoperated with a non-significant $\mathrm{P}$-value for bleeding control.

Foreman et al . reported that bleeding reoperation was one in the sutureless group, and one in the traditional suture ligation group $(2 / 183,1.09 \%) .{ }^{[26]}$

This study had established wound infection in 3 patients (3.26 percent of all patients); the three (8.57 percent) patients were from the traditional suture ligation group. There was no statistical significance for that ( $P$-value was 0.335$)$. They were viewed with conservativity.

Al-Dhahiry et al. study; 3 patients (3.75\%) developed wound infection; 2 patients in the conventional suture ligation group and 1 patient in the suture-free group. The $P$-value $=0.331$ had no statistical meaning for this. They were viewed with conservativity. ${ }^{[6]}$

Total thyroidectomies performed with the sutureless techniques in this study had less postoperative pain. The patients in the sutureless group consumed NSAIDS ampoules during the first 24 hours less than in the conventional suture ligation group as The need for two ampoules showed a significant reduction in the sutureless group $(15,50 \%)$ than in the conventional suture ligation group $(30,85.7 \%)$, the $P$-value was 0.0001 . The need for more than two ampoules during the first 24 hours showed a significant reduction in the sutureless group $(2,6.7 \%)$ than in the conventional suture ligation group $(10,28.6 \%)$, the $P$-value was 0.039 .

Reduced pain by using the harmonic focus, since the amount of electrical energy provided by the harmonic focus is lower than that provided by monopoly or bipolar instruments. The harmonic hemostasis is also done for monopolar or bipolar electrocautery at a temperature of $50{ }^{\circ} \mathrm{C}$ to $100{ }^{\circ} \mathrm{C}$, compared with $150{ }^{\circ} \mathrm{C}$ to $400{ }^{\circ} \mathrm{C}$. It leads to less heat transfer to neighboring structures. Some controversies persist about postoperative pain. There was no impact on postoperative pain concerning the hemostatic technique demonstrated by other authors. ${ }^{[27]}$ Conversely, other investigators have reported a significant reduction in postoperative pain evaluated by visual analog scale scores using Harmonic scalpels. ${ }^{[28]}$

In the research of Zanghì et al; the measurement of postoperative pain demonstrated a moderate decrease in sutureless group distress even in the lack of statistically meaningful variations between the two groups. $^{[27]}$

Many studies showed that sutureless thyroidectomy reduces the post-operative drainage volume. ${ }^{[2]}$ Our results also showed that sutureless total thyroidectomy significantly decreases the postoperative drainage volume with a significant $P$ value $(0.0001)$.

This study reported that the use of the harmonic focus significantly reduced postoperative transient hypocalcemia however, no significant difference regarding permanent hypocalcemia. A similar result was reported by the meta-analysis of Melck, while Garas reported a decreased incidence of hypocalcemia in a sutureless total thyroidectomy group. ${ }^{[30,31]}$

The study done by Cirocchi reported no difference between both groups as regards postoperative hypocalcemia. ${ }^{[32]}$

About recurrent laryngeal nerve function, no significant difference between both groups in this study, a similar result was detected by Luca et al.in their metanalysis. ${ }^{[15]}$ Although Garas and his colleges reported a higher risk of nerve damage in the harmonic focus groups. ${ }^{[30]}$

However, studies done by Carlander et al reported a lower risk of nerve damage in the sutureless thyroidectomy group. ${ }^{[33]}$

Our study reported a significant reduction of overall complications rate in the sutureless thyroidectomy group which is following Ecker et al. ${ }^{[29]}$

The hospital stay was significantly shorter in the sutureless thyroidectomy group in this study due to a decrease in the overall complications rate in the sutureless thyroidectomy group ( $P$-value was 0.0001$)$.

A similar result was detected by Ecker and Garas in their meta-analysis. ${ }^{[29,30]}$ 


\section{CONCLUSION}

The results of this study support the use of Sutureless thyroidectomy as the procedure of choice for the treatment of thyroid diseases as it had shorter operative time, overall complications rate, and good functional results.

The use of the harmonic scalpel was a rapid method for performing total thyroidectomy because it is bloodless, and the combined hemostasis and sectioning in a single instrument. Although the tools are expensive but the reduction of operative time and staff cost makes it cumulatively inexpensive.

\section{ACKNOWLEDGEMENTS}

Special thanks to residents, assistant lectures, and all staff members in the general surgery department Sohag university hospitals for their help and their support.

\section{CONFLICT OF INTEREST}

There are no conflicts of interest.

\section{FUNDING}

The study did not receive any funding.

\section{REFERENCES}

1. Arslan K, Erenoglu B, Dogru O, Ovet G, Turan E, Atay A, Koksal H. Is the superior laryngeal nerve really safe when using a harmonic focus in total thyroidectomy? A prospective randomized study. Asian journal of surgery. 2018 May 1;41(3):222-8.

2. Hannan SA. The magnificent seven: a history of modern thyroid surgery. Int J Surg. 2006;4:187-91.

3. McGreevy PS, Miller FA. Biography of Theodor Kocher Surgery. 1969;65:990.

4. R. Roberto, Adelmo Gi, C. Giovanni, G. Simona, B. Alfonso, P. Raffaele, et al., Int.J. Surg. 12 (2014) $189 \mathrm{e} 193$

5. R. Ciuni, A. Biondi, M.D. Giunta, F. Basile, S. Ciuni, Total thyroidectomy subtotal thyroidectomy for multinodular goiter. Analysis of 1.517 cases, Ann. Ital. Chir. 81 (2010) 9e12.

6. AL-DHAHIRY, Jawad Kadhim S.; HAMEED, Husam Majeed. Total thyroidectomy: Conventional Suture Ligation technique versus sutureless techniques using Harmonic Scalpel or Maximum. Annals of Medicine and Surgery, 2016, 5: 29-34.
7. SINGHAL, Aditya; BASKOTA, Dharma Kant; ACHARYA, Kunjan. Ultrasonic cutting and coagulation device versus conventional diathermy dissection in thyroid surgery: a prospective randomized trial. International Journal of Otorhinolaryngology and Head and Neck Surgery, 2018, 4.2: 335.

8. D. Parmeggiani, M. De Falco, N. Avenia, A. Sanguinetti, A. Fiore, G. Docimo, et al., Nerve sparing sutureless total thyroidectomy. Preliminary study, Ann. Ital. Chir. 83 (2012) 91e96..

9. Kwak HY, Chae BJ, Park YG, Kim SH, Chang EY, $\mathrm{Kim}$ EJ, et al. Comparison of surgical outcomes between papillary thyroid cancer patients treated with the harmonic ACE scalpel and LigaSure precise instrument during conventional thyroidectomy: a single-blind prospective randomized controlled trial, J. Surg. Res. 2014;187:484e489.

10. Mertler CA, Reinhart RV. Advanced and multivariate statistical methods: Practical application and interpretation. Routledge; 2016 Oct 24.

11. Lakens D. Calculating and reporting effect sizes to facilitate cumulative science: a practical primer for t-tests and ANOVAs. Frontiers in psychology. 2013 Nov 26;4:863.

12. Kim HY. Statistical notes for clinical researchers: chi-squared test and Fisher's exact test. Restorative dentistry \& endodontics. 2017 May 1;42(2):152-5.

13. B.H. Lang, S.H. Ng, L.L. Lau, B.J. Cowling, K.P. Wong, A systematic review and meta-analysis comparing the efficacy and surgical outcomes of total thyroidectomy between harmonic scalpel versus ligasure, Ann. Surg. Oncol. 20.(2013) 1918e1926.

14. Contin P, Gooßen K, Grummich K, Jensen K, Schmitz-Winnenthal H, Büchler MW, et al. Energized vessel Seal. Syst. versus CONventional hemostasis Tech. thyroid Surg. -Enercon Syst. Rev. Netw. metaanalysis. 2013;398:1039-56.

15. Revelli L, Damiani G, Bianchi CVNA, Vanella S, Ricciardi W, Raffaelli M, et al. Complications in thyroid surgery. Harmonic Scalpel, Harmonic Focus versus Conventional Hemostasis: A meta-analysis Inter J Surg. 2016;28:S22-32.

16. Melck AL, Wiseman SM. Harmonic scalpel compared to conventional hemostasis in thyroid surgery: a metaanalysis of randomized clinical trials, Int. J. Surg. Oncol. 2010;306079. 
17. Emanuele Ferri, Enrico Armato, Giacomo Spinato, Roberto Spinato, Focusharmonic scalpel compared to conventional hemostasis in open total thyroidectomy: a prospective randomized trial, Int. J. Otolaryngol. 2011 (2011)357195, http://dx.doi. org/10.1155/2011/357195. Epub 2011 Sep. 29..

18. R. Ciuni, A. Biondi, M.D. Giunta, F. Basile, S. Ciuni, Total thyroidectomy vs subtotal thyroidectomy for multinodular goiter. Analysis of 1.517 cases, Ann. Ital. Chir. 81 (2010) 9e12.

19. Kemal Peker, T.D.Z. Ayça, S,. Murat, I_.Abdullah, K. I Kemal, Z. Fatih, A comparison of total thyroidectomies carried out through LigaSure and Harmonic Scalpel: a retrospective study, Turk. J. Med. Sci. 44 (2014) $255 \mathrm{e} 260$.

20. L.Y. Chang, C. O'Neill, J. Suliburk, S. Sidhu, L.Delbridge, M. Sywak, Sutureless total thyroidectomy: a safe and cost-effective alternative, Anz J. Surg. 81(2011) 510e514.

21. Suhaimi MB, Yaakub JA, Muhammad R. An early single institutional experience in sutureless total thyroidectomy. Med J Malaysia. 2012 Apr;67(2):177.

22. A.E. Siperstein, et al., The use of harmonic scalpel vs conventional knot tying for vessel ligation in thyroid surgery, Arch. Surg. 137 (2002) 137e142.

23. Nadim Khan, Adil Bangash, Muzaffaruddin Sadiq, Thyroidectomy with ultrasonic dissector: an early experience at lady reading hospital, J. Postgrad. Med. Inst. 28 (1) (2014) 68e73.

24. G. Docimo, R. Ruggiero, A. Gubitosi, G. Casalino, A. Bosco, S. Gili, et al., Ultrasoundscalpel in thyroidectomy. The prospective randomized study, Ann. Ital.Chir. 83 (6) (2012) 491e496.

25. A.C. Matteo, L.B. Salvatore, B. Laura, C. Andrea, B. Antonino, The use of Focus Harmonic scalpel compared to conventional hemostasis for thyroid surgery: a prospective randomized study, Cannizzaro al. SpringerPlus 3 (2014) 639. http://www.springerplus.com/content/3/1/639.

26. E. Foreman, S. Aspinall, R.D. Bliss, Twj Lennard, Use of harmonic scalpel in thyroidectomy: 'beyond the learning curve', Ann. R. Coll. Surg. Engl. 91 (2009)214e216.

27. Zanghì A, Cavallaro A, Di Vita M, Cardì F, Di Mattia P, Piccolo G, Barbera G, Urso M, Cappellani A. The safety of the Harmonic ${ }^{\circledR}$ FOCUS in open thyroidectomy: a prospective, randomized study

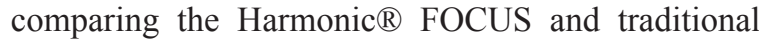
suture ligation (knot and tie) technique. International Journal of Surgery. 2014 Aug 1;12:S132-5.

28. T.S. Papavramidis, K. Sapalidis, N. Michalopoulos, K. Triantafillopoulou, G. Gkoutzamanis, I. Kesisoglou, et al., Ultracision harmonic scalpel versus clampand- tie total thyroidectomy: clinical trial, Head. Neck Surg. 32 (6)(2010) $723 \mathrm{e} 727$.

29. Ecker T, Carvalho AL, Choe JH, Walosek G, Preuss KJ. Hemostasis in thyroid surgery: harmonic scalpel versus other techniques: a meta-analysis, Otolaryngol. Head Neck Surg. J. 2010;143:17-25.

30. Garas G, Okabayashi K, Ashrafian H, Shetty K, Palazzo $\mathrm{F}$, Tolley $\mathrm{N}$, et al. Zacharakis, Which hemostatic device in thyroid surgery? A Network meta-analysis of surgical Technologies, Thyroid. 2013:1138-50.

31. Melck AL, Wiseman SM. Harmonic scalpel compared to conventional hemostasis in thyroid surgery: a metaanalysis of randomized clinical trials, Int. J. Surg. Oncol. 2010;306079.

32. Cirocchi R, D'Ajello F, Trastulli S, Santoro A, Rocco GD, Vendettuoli D, et al. Avenia, Meta-analysis of thyroidectomy with ultrasonic dissector versus conventional clamp and tie, World J. Surg. Oncol. 2010;23:8-112.

33. Carlander J, Koch C, Brudin L, Nordborg C, Gimm $\mathrm{O}$, Johansson $\mathrm{K}$. Heat production, nerve function, and morphology following nerve close dissection with surgical instruments, World J. Surg. 2012;36:1361-7. 